\title{
Ecological effects of marine reserves in Latin America and the Caribbean
}

\author{
A. Paulina Guarderas ${ }^{1,2}$, Sally D. Hacker ${ }^{1, *}$, Jane Lubchenco ${ }^{1}$ \\ ${ }^{1}$ Department of Zoology, Oregon State University, Corvallis, Oregon 97331-2914, USA \\ ${ }^{2}$ Present address: Instituto Nazca de Investigaciones Marinas, Núñez de Vela N36-121 and Corea, Edif. Karolina 2000, \\ dept. 90, Quito EC 170102, Ecuador
}

\begin{abstract}
In this study we evaluated the performance of marine reserves in Latin America and the Caribbean by examining the results of previously published studies. On average, the total biomass, density and body size of species increased inside marine reserves but species richness did not. The magnitude and direction of the responses in particular reserves varied depending on the species and trophic group considered, suggesting that indirect effects and trophic cascades might be important processes in the community-wide response to protection. Our analysis at the species level showed that most species increased in density inside reserves and that the fish response was greater than that of the invertebrate response, which was more variable. We also found a positive relationship between recovery of particular species and their individual level of exploitation intensity outside the reserve but found no such relationship with species body size, mobility, trophic level or resilience (population doubling time). Moreover, our analysis revealed that the response to protection was unaffected by the size, years of protection or area surveyed of the reserve, but there was a negative relationship with the number of species sampled in the studies. Our results also showed that the number of publications on marine reserve performance in Latin America and the Caribbean is still limited and the distribution is geographically uneven. We suggest that a stronger focus on both target species and the suite of other interacting species will allow better estimates of the community-wide effects of protection.
\end{abstract}

KEY WORDS: Marine reserves - Latin America - Caribbean - Response to protection · Density • Biomass $\cdot$ Body size $\cdot$ Species richness

\section{INTRODUCTION}

Anthropogenic activities are increasingly affecting the world's oceans (Jackson et al. 2001, Harley et al. 2006, Worm et al. 2006, Halpern et al. 2008). Overfishing has been identified as one of the major threats to marine systems due to the direct effects which it has on the population decline of numerous species (e.g. Myers $\&$ Worm 2005), the indirect effects on food webs (e.g. Pauly et al. 1998) and the destruction of marine habitats (e.g. MEA 2006).

Marine reserves, which are areas protected from extractive activities, potentially constitute a powerful conservation tool for counteracting the harmful effects of fishing by providing spatial refuges for fished popu- lations and protecting important habitats and associated ecological interactions and functions (NRC 2001, Lubchenco et al. 2003, Sobel \& Dahlgren 2003). Recent syntheses of data from many reserve sites have shown that overall density, biomass, body size and species richness of marine organisms are consistently higher inside marine reserves than in nearby fished sites (e.g. Côté et al. 2001, Halpern 2003, Lester et al. 2009). These positive overall effects of reserves are being described for a variety of marine species and communities and at a variety of locations around the world (Lester et al. 2009).

However, it is clear from the syntheses conducted thus far that marine reserves can have different effects on different species and communities. One obvious dif- 
ference among species relates to their history of exploitation prior to reserve establishment (Côté et al. 2001). For instance, because fishing mainly targets species from higher trophic levels (Pauly et al. 1998); large predators are likely to benefit from protection, however their recovery rates may be slow due to their slower growth and reproduction (Jennings et al. 1999). There is evidence that older marine reserves near more recently established reserves can have higher biomasses for some fish species (Francini-Filho \& Moura 2008a). Dispersal ability is another characteristic that may differentially affect the response of individual species and communities to reserve protection. Marine reserves protect sedentary species more effectively (Jennings 2001) than they protect highly mobile species, which need a reserve that encompasses most of their range (Gerber et al. 2003). However, some highly mobile species can show positive responses to protection if a proportion of the population has a high level of site fidelity as a result of home range behavior (Gell \& Roberts 2003).

In addition to the direct effects of reserves on fished species, there are many indirect effects that can have both positive and negative consequences for nonfished species within reserve communities (Pinnegar et al. 2000). The most obvious effects occur when increases in predators or herbivores influence lower trophic levels. For example, the dominant species in benthic communities in the Leigh Marine Reserve, New Zealand, shifted from sea urchins to macroalgae when predators were protected from fishing pressure (Shears \& Babcock 2003).

Given the potential direct benefits of marine reserves, and the uncertain indirect effects that may arise, it is crucial to understand the patterns of change following their establishment. In this study we evaluated the biological performance of marine reserves at the large regional scale of Latin America and the Caribbean, where a comprehensive synthesis of the effect of marine reserves has been lacking (see Appeldoorn \& Lindeman 2003 for the Caribbean and Guarderas et al. 2008 for both areas). Widespread overfishing and degradation in many coastal ecosystems in this region makes such an evaluation timely (see Cortés 2003, Guarderas et al. 2008). Latin American and Caribbean countries experience similar levels of development, socio-economic structure and sources of production, making them a natural group to consider as one region (UNEP 2001).

We address the following questions: (1) Are total biomass, density, body size and richness of the species surveyed higher in marine reserves? If so, how do these values compare with other studies? (2) Are there different responses across trophic groups (corals, macroalgae, herbivores and predators) and taxonomic groups (fishes and invertebrates)? (3) What are the important characteristics of species and reserves that determine the magnitude of their responses?

\section{MATERIALS AND METHODS}

A literature survey was conducted to assemble studies on the ecological effects of marine reserves in Latin America and the Caribbean. The keywords used in the search were: marine protected areas, marine reserves, and marine parks. We searched 4 databases from 1970 to 2007: Aquatic Sciences and Fisheries Abstracts, Oceanic Abstracts, Environmental Sciences and the Zoological Record Plus Database. References cited in these publications were also evaluated for use in the present analysis. Peer-reviewed studies and technical reports that quantitatively evaluated biological effects of total protection from extractive activities were included. We focused on marine reserves in Latin American and Caribbean countries that (1) were established at least $3 \mathrm{yr}$ before their effects were evaluated, (2) were considered to be at least moderately enforced based on information obtained from the publications and (3) compared the effects of marine reserves to fished areas at one (i.e. control-impact designs, C-I) or multiple points in time (i.e. before-after control-impact [BACI] designs). With this methodology, data from 23 reserves and 32 publications were identified and used in the analysis (Table S1 in the supplement at www. int-res.com/articles/suppl/m429p219_supp.pdf).

To quantify the effect of protection inside marine reserves compared with fished areas, we calculated the response ratio $(\mathrm{RR})$ as the $\left[\ln \left(\mathrm{N}_{\text {inside }} / \mathrm{N}_{\text {outside }}\right)\right]$, defined as the natural $\log$ of the ratio of the biological variable of interest inside the reserve divided by that outside the reserve. This metric has the least bias of several metrics and its sampling distribution is approximately normal (Hedges et al. 1999). When studies included a BACI design, the biological variable quantified inside the reserve after its establishment was divided by the biological variable obtained before the reserve establishment. This ratio was then compared with temporal changes outside the reserve $\left[\ln \left(\mathrm{N}_{\text {After Inside }} / \mathrm{N}_{\text {Before Inside }}\right) /\left(\mathrm{N}_{\text {After Outside }} / \mathrm{N}_{\text {Before Outside }}\right)\right]$. We did not weight the response ratio values by their precision because some studies were not replicated or did not report estimates of variability. This would have severely reduced our sample size and potentially introduced biases into our dataset. However, to minimize the statistical errors associated with not weighting the RRs that potentially did not meet distributional assumptions and the small sample sizes in some cases, we calculated confidence intervals $( \pm 95 \% \mathrm{CI}$ ) around the means using bias-corrected percentile bootstrap- 
ping (1000 iterations with replacement) (Adams et al. 1997). Mean response ratios were considered to be statistically significant if their confidence intervals did not overlap zero (Rosenberg et al. 2000). Analyses were conducted with the software package MetaWin (Rosenberg et al. 2000).

When data from the studies were provided for a number of locations within and outside each reserve (Table S1), they were converted to a single mean value for the reserve and control areas. In addition, if different studies evaluated the performance of the same reserve (Table S1), averages were taken across studies to obtain an overall reserve response. We chose an average value because different species or assemblages were generally evaluated in different studies. However, when data for the same set of species were evaluated in different publications from the same locations within the reserve, but at distinct points in time, only the most recent publication date was selected. For those studies that evaluated the performance of marine reserves at distinct points in time, the most recent data were compared with the baseline in order to include the longest duration of protection. Finally, given the variability in the types of data reported, our analyses were conducted at 3 levels: (1) total reserve effects, (2) trophic and taxonomic group effects and (3) species effects (Table S1). The species reported in the surveys and used in the analyses are given in Table S2 in the supplement at www.int-res.com/articles/suppl/m429 p219_supp.pdf.

To evaluate the overall effect of reserves, we calculated the $\mathrm{RR}$ for total density ( $\mathrm{n}=19$ reserves), biomass ( $\mathrm{n}=11$ reserves), body size $(\mathrm{n}=11$ reserves) and reserve species richness ( $\mathrm{n}=5$ reserves) of all the species surveyed in reserves for which data were available (Tables S1 \& S2). To test for the contribution of different reserve characteristics (reserve size and years of protection) and different sampling methods (number of species sampled and area surveyed) to the response of reserves, we conducted regression analyses using the $\mathrm{RR}$ for density, as this was the most frequent response variable recorded in the literature (19 reserves).

To evaluate the effects of reserves on different trophic groups, we calculated the RR for corals $(\mathrm{n}=6$ reserves), macroalgae ( $\mathrm{n}=7$ reserves), herbivores ( $\mathrm{n}=$ 7 reserves) and fish predators ( $n=7$ reserves) using biomass, density or percent cover as the response variables, depending on the study (Table S1). The reserves used in these analyses were all in the Caribbean.

To measure the effects of reserves on individual species, we collected data from 16 reserves that reported individual species responses to protection (Tables S1 \& S2). We identified 186 species, 131 of which were fishes and 55 of which were invertebrates, and again calculated RR using density as the response variable.
In addition, to understand the relationship between species responses to protection and various characteristics of species within the reserves, we correlated individual species response variables and the independent variables of exploitation intensity, maximum body size, adult mobility, trophic level and resilience for each reserve. In order to have sufficient degrees of freedom these correlations are based only on data from reserves that evaluated the effects of protection of at least 3 species. Data from 9 reserves (141 species in total) fulfilled our criteria.

The species' characteristics used in the analyses above were determined with the information provided in Froese \& Pauly's (2007) database 'FishBase' and in region-specific literature for marine invertebrates (Humann \& DeLoach 2002, Gotshall 2005, BrionesFourzán et al. 2006). Based on exploitation information in FishBase, exploitation intensity was categorized and values assigned as: no exploitation (1), minor commercial (2), commercial (3) or high commercial exploitation (4) (information on recreational and artisanal fishing intensity was not available; therefore, we were not able to assign this variable a value). Maximum body size of the species in the studies ranged between 7 and $300 \mathrm{~cm}$. Adult mobility was categorized and values assigned based on whether the species was oceanodromous (1), reef associated (2), benthic (3) or sessile (4). Trophic level values, based on Froese \& Pauly (2007), were given for herbivores (2 to 2.19), secondary and tertiary consumers $(>2.8)$ and omnivores (2.2 to 2.79). Finally, resilience was defined as the minimum time required to double the population size and was only recorded for the fish species. The values based on Froese \& Pauly (2007) include very low resilience $(>14 \mathrm{yr})$, low resilience (4.5 to $14 \mathrm{yr})$, medium resilience (1.4 to $4.4 \mathrm{yr}$ ) and high resilience $(<15 \mathrm{mo})$.

\section{RESULTS AND DISCUSSION}

We found an overall positive response of marine reserves at the reserve, trophic group and species level. Total density, biomass and body size of species were significantly greater inside marine reserves than in fished areas (Fig. 1). In part, a similar response for these 3 variables is expected, given the covariance between density and body size and biomass (although they have high density, small organisms can also have low biomass). Species richness, however, did not show a statistically significant change inside versus outside reserves (Fig. 1). Our results corroborate the findings of other studies (Halpern 2003, Lester et al. 2009), but the magnitudes of the responses are lower, possibly owing to smaller sample sizes. This may be especially important for the detection of changes in species rich- 


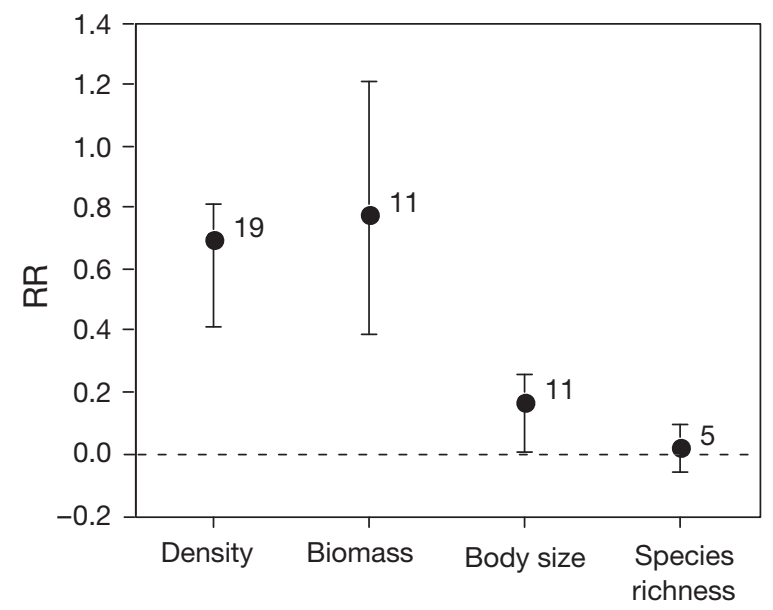

Fig. 1. Average $( \pm 95 \% \mathrm{CI})$ response ratios (RR) of marine reserves in Latin America and the Caribbean as measured by total density $(n=19)$, biomass $(n=11)$, body size $(n=11)$ and reserve species richness $(n=5)$. See Table $S 1$ in the supplement for reserves used in the analysis

ness with protection; only 5 marine reserves had species richness data. Additionally, the differences in magnitude of the effects of protection may be related to latitudinal trends. A recent global review of the effects of marine reserves demonstrated that temperate reserves show equal and, in some cases, greater effects compared with tropical reserves (Lester et al. 2009). Because we found many more studies that evaluated the performance of tropical marine reserves, mostly in the Caribbean (tropics: 19 reserves, temperate: 4 reserves; Table S1), the estimation of the overall effects from protection was highly influenced by the performance of those reserves.

When studies reported the effect of protection at the trophic group level, we found that the magnitude of recovery was more evident for predatory fishes than for other trophic groups including herbivores, macroalgae and corals (Fig. 2). This may be due in part to the wide variability in the response of particular reserves and the interaction between different trophic levels within them. For example, the Exuma Cays Land and Sea Park in the Bahamas, where there has been 2 decades of protection and a high degree of isolation (Mumby et al. 2006), shows dramatic increases in the biomass of top predators and fish herbivores (Fig. 2). This caused an increase in grazing inside the reserve and led to a major reduction in macroalgal cover (Mumby et al. 2006, Fig. 2). The control of macroalgae could have important effects on vulnerable coral reefs by reducing competition and allowing better survivorship and recruitment (Hughes et al. 2007, but see Bruno et al. 2009). Unfortunately, coral cover was not measured in Mumby et al. (2006). Another reserve, Punta Frances, Cuba, showed a large increase in

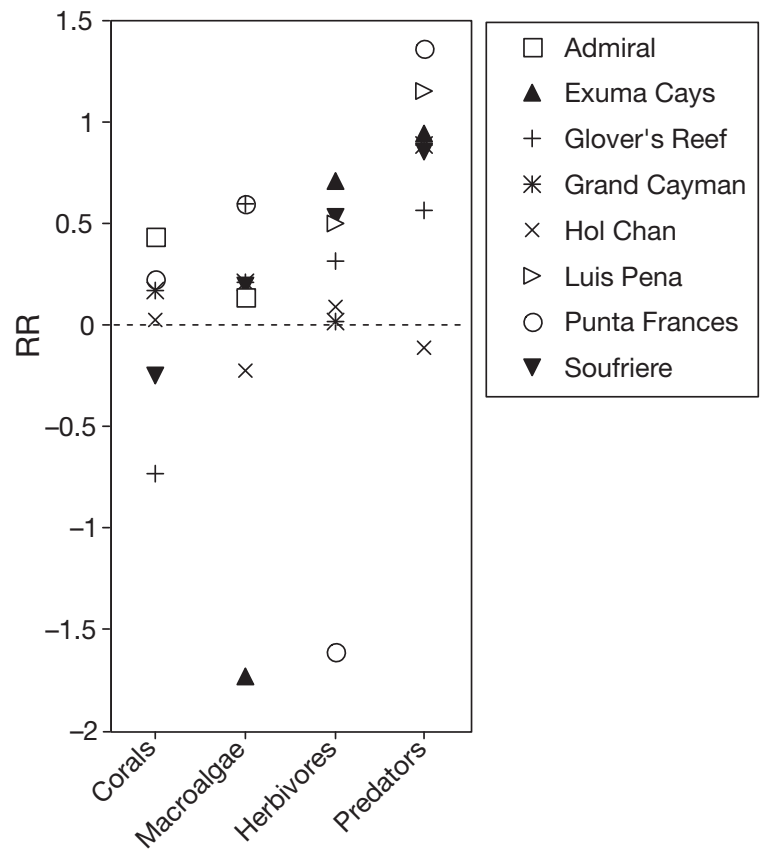

Fig. 2. Average $( \pm 95 \% \mathrm{CI})$ response ratios (RR) for different trophic groups (corals, macroalgae, herbivores and predators) in 8 reserves in the Caribbean. RR was calculated using density, biomass or percent cover, depending on the study analyzed. See Table S1 for reserves used in the analysis

predators, a dramatic decline in herbivores, and an increase in macroalgae (Fig. 2). This pattern suggests there is a strong trophic cascade driven by an increase in fish predators. Interestingly, there was also an increase in coral cover (Fig. 2), suggesting that the potential competitive effect of macroalgae was outweighed by the overall effect of the reserve. This was not the case at Glover's Reef where there was a large increase in macroalgae and a decline in coral cover, potentially driven by more predators (Fig. 2).

We also found that at the species level, density increased inside compared with outside reserves (average $\mathrm{RR}=0.22, \mathrm{CI}=+0.08$ to $-0.07, \mathrm{n}=186$ species), and this was significantly different from zero. When we separated the responses based on whether the species were fishes or invertebrates we found that the fish response was greater (average $\mathrm{RR}=0.28, \mathrm{CI}=$ +0.08 to $-0.07, \mathrm{n}=131$ species) than that of the invertebrates (average $\mathrm{RR}=0.15, \mathrm{CI}=+0.18$ to $-0.16, \mathrm{n}=55$ species). Overall, invertebrates showed higher variation in responses to protection and exhibited the most extreme responses, both positive and negative (RR ranged from -1 to +2.15 ), and they were not different from zero. Extreme positive responses in invertebrates may relate to their relatively low mobility, high intensity of exploitation, high reproductive rates and short life spans. Some of the highest positive responses shown in our review are from a spiny lobster (Acosta \& 
Robertson 2003) and a carnivorous gastropod (Durán \& Castilla 1989).

Our species level analysis across reserves showed that only one variable, intensity of exploitation outside the reserve, was positively correlated, on average, with the response ratio for individual species (Fig. 3), and this was significantly different from zero. This intuitively simple result not only supports previous findings that evaluated the effects of marine reserves on fish species (Mosquera et al. 2000, Côté et al. 2001, Micheli et al. 2004), but also demonstrates that this relationship holds when fish and invertebrate species are both included in the analysis. The lack of correlation between response ratios at the species level and the separate variables of body size, mobility, trophic level and resilience for each reserve (Fig. 3) could be due to covariance among these variables. For example, large-bodied species are likely to be highly mobile as adults, occur at high trophic levels and have low population resilience. In addition, the lack of a consistent positive correlation could reflect the type of fishing that occurs in this region. Contrary to other locations where overfishing operates gradually from high to low trophic levels (Pauly et al. 1998), the Caribbean seems to show similar overharvesting among trophic levels. This pattern is attributed to the widespread use of nonselective fishing gear and the high density of fishers in small areas (Jackson et al. 2001). In addition, there is a strong focus on invertebrate fishing, particularly lobster and conch, in the Caribbean.

Moreover, negative or no correlation between species' responses and certain characteristics could be evidence of indirect effects, as shown in Fig. 2. For example, the lowest species response to protection in our dataset comes from the mussel Perumytilus purpuratus. It is the main prey of a carnivorous gastropod, Concholepas concholepas, which increased dramatically in numbers in intertidal marine reserves in Chile (Durán \& Castilla 1989). The decrease in mussel abundance led to a well-documented trophic cascade in which barnacles and algae increased in the presence of Concholepas (Durán \& Castilla 1989, Castilla 1999). These indirect effects may be the main driving factors resulting in the inability to detect whether certain characteristics of species influence their responses to protection.

We also found, as have other studies (e.g. Halpern 2003, Lester et al. 2009), that the response of these reserves was unaffected by their size, years of protection or the area surveyed (Fig. $4 \mathrm{a}-\mathrm{C}$ ), but there was a significant negative rela-

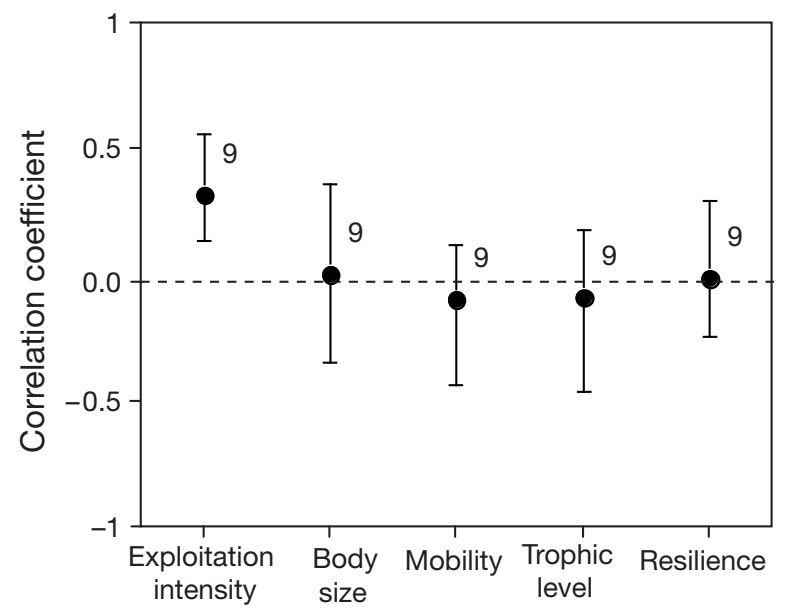

Fig. 3. Average $( \pm 95 \% \mathrm{CI})$ correlation coefficients for species response ratios and species-specific characteristics (exploitation intensity, body size, mobility, trophic level and resilience; see 'Materials and methods' for categorical variable determination) in 9 marine reserves in Latin America and the Caribbean. See Tables S1 and S2 for reserves and species used in the analysis
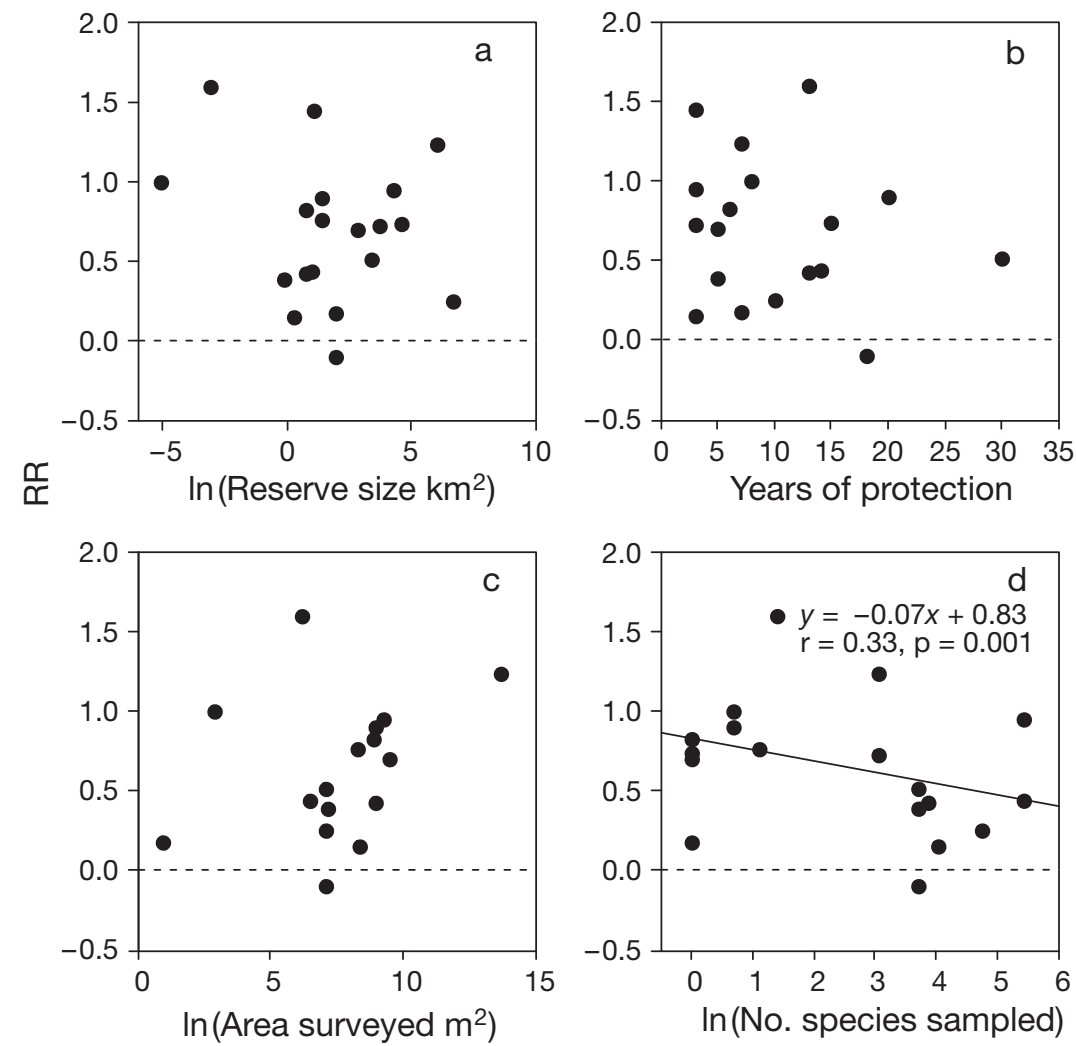

Fig. 4. Relationship between the response ratio (RR) and the reserve characteristics (a) reserve size, (b) years of protection, (c) area surveyed and (d) number of species sampled, using density values from 19 marine reserves in Latin America and the Caribbean. See Table S1 for reserves used in the analysis 
tionship with the number of species sampled in the study (Fig. 4d). By sampling only one or a few species, it is more likely that extreme outcomes (either highly positive or negative) will be recorded for a particular reserve both because of the small sample sizes and the common focus on a few organisms that are targeted to show positive outcomes to protection. This approach is valid in terms of monitoring specific goals of reserves such as rebuilding populations of particular species severely depleted by fishing. However, it may overestimate or underestimate the effect of protection on the entire community. Thus, defining clear goals for marine reserves is important not only for monitoring efforts but also for the ecological scale from which expected outcomes may be inferred (Appeldoorn \& Lindeman 2003).

We suggest that to fully understand the effect of marine reserves, monitoring and data analysis should assess the effects of protection on (1) target species and (2) other interacting species, in particular trophic or taxonomic groups that better represent the community as a whole. As we have shown, this is important in terms of detecting indirect effects and more reasonably estimating community-wide effects of protection. Additionally, long-term monitoring programs that use BACI designs are needed. These will not only help control for the sometimes considerable variation in space and time in order to evaluate the effects of protection inside reserve boundaries (e.g. see FranciniFilho \& Moura 2008a), but will also help determine (indirectly) the extent of spillover and propagule dispersal from marine reserves (Castilla et al. 2007, Francini-Filho \& Moura 2008b). If spillover effects occur, they can confound the results of protection and possibly result in no or little measurable response. Ways to detect this effect could include monitoring biological variables along a gradient from the reserve boundary (Chapman \& Kramer 1999, Francini-Filho \& Moura 2008b) or measuring the fishing effort in the adjacent fished areas (Roberts et al. 2001). Intensity of exploitation is also a critical factor that should be accounted for in the reserve evaluation process because it will greatly determine the real and perceived effects of protection (Mosquera et al. 2000, Halpern 2003, Lester et al. 2009, our Fig. 3).

Finally, our results show that the number of publications on marine reserve performance in Latin America and the Caribbean is still limited and the distribution is geographically uneven. The majority of marine reserves and studies are located in the Caribbean and thus are tropical (Table S1, Guarderas et al. 2008). It is unfortunate that quantitative information exists for only $\sim 25 \%$ of no-take reserves or zones within multiple-use Marine Protected Areas in this region of the world (Guarderas et al. 2008). We emphasize the need for more studies that document the community-wide effects of marine reserves and the need to make such findings available in peer-reviewed journals.

Acknowledgements. We thank A. Saenz and J. Torre for providing data. This manuscript was improved by comments from E. Seabloom, K. Grorud-Colvert, L. Vinueza, P. Zarnetske and $M$. Hessing-Lewis. We acknowledge financial support from the David and Lucile Packard Foundation to J.L. and S.H. and from the Oregon Sea Grant and PEO Sisterhood International Peace Scholarship to A.G.

\section{LITERATURE CITED}

Acosta CA, Robertson DN (2003) Comparative spatial ecology of fished spiny lobsters Panulirus argus and an unfished congener $P$. guttatus in an isolated marine reserve at Glover's Reef atoll, Belize. Coral Reefs 22:1-9

Adams DC, Gurevitch J, Rosenberg MS (1997) Resampling tests for meta-analysis of ecological data. Ecology 78: $1277-1283$

Appeldoorn RA, Lindeman KC (2003) Caribbean-wide survey of marine reserves: spatial coverage and attitudes of effectiveness. In: Appeldoorn R (ed) Caribbean marine protected areas: practical approaches to achieve economic and conservation goals. Gulf Caribb Res 14, University of Mississippi, Ocean Springs, MS

Briones-Fourzán P, Pérez-Ortiíz M, Lozano-Álvarez E (2006) Defense mechanisms and antipredator behavior in two sympatric species of spiny lobsters, Panulirus argus and P. guttatus. Mar Biol 149:227-239

Bruno JF, Sweatman H, Precht WF, Selig ER, Schutte VG (2009) Assessing evidence of phase shifts from coral to macroalgal dominance on coral reefs. Ecology 90: $1478-1484$

Castilla JC (1999) Coastal marine communities: trends and perspectives from human-exclusion experiments. Trends Ecol Evol 14:280-283

Castilla JC, Campo MA, Bustamante RH (2007) Recovery of Durvillea antarctica (Durvilleales) inside and outside Las Cruces marine reserve, Chile. Ecol Appl 17:1511-1522

> Chapman MR, Kramer DL (1999) Gradients in coral reef fish density and size across the Barbados Marine Reserve boundary: effects of reserve protection and habitat characteristics. Mar Ecol Prog Ser 181:81-96

Cortés J (2003) Latin American coral reefs. Elsevier, San Pedro

Côté IM, Mosqueira I, Reynolds JD (2001) Effects of marine reserve characteristics on the protection of fish populations: a meta-analysis. J Fish Biol 59:178-189

> Durán LR, Castilla JC (1989) Variation and persistence of the middle rocky intertidal community of central Chile, with and without human harvesting. Mar Biol 103:555-562

> Francini-Filho RB, Moura RL (2008a) Dynamics of fish assemblages on coral reefs subjected to different management regimes in the Abrolhos Bank, eastern Brazil. Aquat Conserv 18:1166-1179

> Francini-Filho RB, Moura RL (2008b) Evidence for spillover of reef fishes from a no-take marine reserve: an evaluation using the before-after control-impact (BACI) approach. Fish Res 93:346-356

Froese RP, Pauly D (2007) FishBase. www.fishbase.org (accessed April 2007)

Gell F, Roberts CM (2003) Benefits beyond boundaries: the fishery effects of marine reserves. Trends Ecol Evol 18: 448-455 
Gerber LR, Bostford LW, Hastings A, Possingham H, Gaines S, Palumbi SR, Andelman S (2003) Population models for marine reserve design: a retrospective and prospective synthesis. Ecol Appl 13(Suppl Mar Reserv):47-64

Gotshall DW (2005) Guide to marine invertebrates: Alaska to Baja California. Sea Challengers, Monterey, CA

$>$ Guarderas AP, Hacker SD, Lubchenco J (2008) Current status of marine protected areas in Latin American and the Caribbean. Conserv Biol 22:1630-1640

Halpern B (2003) The impact of marine reserves: Do reserves work and does reserve size matter? Ecol Appl 13(Suppl Mar Reserv):117-137

Halpern BS, Walbridge S, Selkoe KA, Kappel CV and others (2008) A global map of human impact on marine ecosystems. Science 319:948-952

Harley CDG, Randall Hughes A, Hultren KM, Miner BG and others (2006) The impact of climate change in coastal marine systems. Ecol Lett 9:228-241

Hedges LV, Gurevitch J, Curtis P (1999) The meta-analysis of response ratios in experimental ecology. Ecology 80: 1150-1156

Hughes TP, Bellwood DR, Folke CS, McCook LJ, Pandolfi JM (2007) No-take areas, herbivory and coral reef resilience. Trends Ecol Evol 22:1-3

Humann P, DeLoach N (2002) Reef creature identification. Florida, Caribbean, Bahamas. New World, Jacksonville, FL

Jackson J, Kirby M, Berger W, Bjorndal K and others (2001) Historical overfishing and the recent collapse of coastal ecosystems. Science 293:629-638

Jennings S (2001) Patterns and predictions of population recovery in marine reserves. Rev Fish Biol Fish 10: 209-231

Jennings S, Greenstreet S, Reynolds JD (1999) Structural change in an exploited fish community: a consequence of differential fishing effects on species with contrasting life histories. J Anim Ecol 68:617-627

Lester SE, Halpern BS, Grorud-Colvert K, Lubchenco J and others (2009) Biological effects within no-take marine reserves: a global synthesis. Mar Ecol Prog Ser 384:33-46

Lubchenco J, Palumbi SR, Gaines S, Andelman S (2003) Plugging a hole in the ocean: the emerging science of marine reserves. Ecol Appl 13(Suppl Mar Reserv):3-7

MEA (Millennium Ecosystem Assessment) (2006) Marine and coastal ecosystem and human well-being: a synthesis

Editorial responsibility: Romuald Lipcius, Gloucester Point, Virginia, USA report based on the findings of the Millennium Ecosystem Assessment. United Nations Environment Programme. Island Press, Washington, DC

> Micheli F, Halpern BS, Botsford LW, Warner RR (2004) Trajectories and correlates of community change in no-take marine reserves. Ecol Appl 14:1709-1723

Mosquera I, Coté IM, Jennings S, Reynolds JD (2000) Conservation benefits of marine reserves for fished populations. Anim Conserv 3:321-332

Mumby PJ, Dahlgren C, Harbone AR, Kappel C and others (2006) Fishing, trophic cascades, and the process of grazing on coral reefs. Science 311:98-101

Myers RA, Worm B (2005) Extinction, survival or recovery of large predatory fishes. Phil Trans R Soc B Biol Sci 360: 13-20

NRC (National Resource Council) (2001) Marine protected areas: tools for sustaining ocean ecosystems. National Academy, Washington, DC

Pauly D, Christensen V, Dalsgaard J, Froese R, Torres F (1998) Fishing down marine food webs. Science 279: 860-863

Pinnegar JK, Polunin NVC, Francour P, Badalamenti F and others (2000) Trophic cascades in benthic marine ecosystems: lessons for fisheries and protected-area management. Environ Conserv 27:179-200

Roberts CM, Bohnsack JA, Gell F, Hawkins JP, Goodridge R (2001) Effects of marine reserves on adjacent fisheries. Science 294:1920-1923

Rosenberg MS, Adams DC, Gurevitch J (2000) Meta-Win: statistical software for meta-analysis, Version 2. Sinauer Associates, Sunderland, MA

Shears NT, Babcock RC (2003) Continuing trophic cascade effects after 25 years of no-take marine reserve protection. Mar Ecol Prog Ser 246:1-16

Sobel J, Dahlgren C (2003) Marine reserves. A guide to science, design, and use. Island Press, Washington, DC

UNEP (United Nations Environmental Programme) (2001) Municipal waste water as a land-base source of pollution in coastal and marine areas of Latin America and the Caribbean. UNEP, Regional Office for Latin America and the Caribbean, Mexico City

Worm B, Barbier EB, Beaumont N, Duffy E and others (2006) Impacts of biodiversity loss on ocean ecosystem services. Science 314:787-790

Submitted: April 29, 2010; Accepted: February 22, 2011 Proofs received from author(s): May 5, 2011 